\title{
Association of Fluid Management with Outcome in Invasively Ventilated COVID-19 ARDS Patients - Insights From the PRoVENT-COVID Study: A National, Multicenter, Observational Cohort Analysis.
}

\section{Sanchit Ahuja}

Henry Ford Hospital

Harm-Jan de Grooth

Amsterdam UMC, location VU Medical Center

\section{Frederique Paulus}

Amsterdam UMC, location AMC, Amsterdam, The Netherlands

\section{Fleur van der Ven}

Amsterdam UMC, location AMC, Amsterdam, The Netherlands

\author{
Ary Serpa Neto \\ University of Melbourne \\ Marcus J. Schultz ( $\nabla$ m.j.schultz@amsterdamumc.nl ) \\ Amsterdam UMC, location AMC, Amsterdam, The Netherlands \\ Pieter Roel Tuinman \\ Amsterdam UMC, location VU Medical Center
}

\section{Research Article}

Keywords: cumulative fluid balance, liberation of ventilation, COVID-19, ARDS, critical care

Posted Date: January 28th, 2022

DOI: https://doi.org/10.21203/rs.3.rs-1293335/v1

License: (c) (i) This work is licensed under a Creative Commons Attribution 4.0 International License.

Read Full License 


\section{Abstract}

Background: Increasing evidence indicates the potential benefits of restricted fluid management in critically ill patients. Evidence lacks on the optimal fluid management strategy for invasively ventilated COVID-19 patients. We hypothesized that the cumulative fluid balance would affect the successful liberation of invasive ventilation in COVID-19 patients with acute respiratory distress syndrome (ARDS).

Methods: We analyzed data from the multicenter observational 'PRactice of VENTilation in COVID-19 patients' (PRoVENT-COVID) study. Patients with confirmed COVID-19 and ARDS who required invasive ventilation during the first 3 months of the international outbreak (March 1, 2020, to June 2020) across 22 hospitals in the Netherlands were included. The primary outcome was successful liberation of invasive ventilation, modeled as a function of day 3 cumulative fluid balance using Cox proportional hazards models, using the crude and the adjusted association. Sensitivity analyses without missing data and modeling ARDS severity were performed.

Results: Among 650 patients, three groups were identified. Patients in the higher, intermediate and lower groups had a median cumulative fluid balance of 1.98 liters (1.27-7.72 liter), 0.78 liter (0.26-1.27 liter) and -0.35 liter (-6.52-0.26 liter), respectively. Higher day 3 cumulative fluid balance was significantly associated with a lower probability of successful ventilation liberation (adjusted hazard ratio $0.85,95 \% \mathrm{Cl}$ $0.77-0.94, P=0.0013)$. Sensitivity analyses showed similar results.

Conclusions: In a cohort of invasively ventilated patients with COVID-19 and ARDS, a higher cumulative fluid balance was associated with a longer ventilation duration, indicating that restricted fluid management in these patients may be beneficial.

Trial registration: Clinicaltrials.gov (NCT04346342); Date of registration: April 15, 2020

\section{Background}

Acute respiratory failure necessitating invasive ventilation is considered one of the leading causes of death in patients with COVID-19 [1]. [2-4]. Intravenous fluid therapy remains one of the cornerstones of resuscitation for nearly all forms of shock. While early fluid resuscitation is critical in managing shock, the accumulation of positive fluid balance has also been associated with worsening acute respiratory distress syndrome (ARDS). A previous study of non-COVID-19 patients with ARDS suggests that a higher positive cumulative fluid balance is independently associated with mortality, longer ventilation duration, and extended intensive care unit (ICU) stay [5]. Based on this indirect evidence, consensus guidelines during the early stages of the pandemic on the management of shock in patients with COVID-19 recommended targeting a neutral fluid balance strategy [6].

Considerable evidence from observational studies, clinical trials, and systematic reviews indicate the potential benefits of restricting fluid administration in critically ill patients [7-9]. Excessive fluid administration may increase the risk of pulmonary complications and the effects of edema in vital 
organs, causing injury [10]. However, a restrictive fluid strategy could lead to extrapulmonary organ dysfunction consequent to reduced cardiac output. Therefore, the fluid balance being an adverse prognostic factor, yet also a potentially modifiable risk factor, pose a unique dilemma in the management of critically ill COVID-19 patients. Current evidence is insufficient and constantly evolving to best address the optimal fluid management strategy in invasively ventilated COVID-19 patients. Using the database of the multicenter observational 'PRactice of VENTilation in COVID-19 patients' (PRoVENT-COVID) study, we investigated cumulative fluid balance in invasively ventilated COVID-19 and ARDS patients and factors associated with a higher positive cumulative fluid balance. We aimed to test the association between the cumulative fluid balance during the first 4 calendar days of invasive ventilation and successful liberation of ventilation in these patients. We hypothesized that a higher cumulative fluid balance is independently associated with a lower probability of successful liberation of invasive ventilation in COVID-19 ARDS patients.

\section{Methods}

\section{Design}

PRoVENT-COVID is an investigator-initiated national, multicenter, observational cohort study that included COVID-19 patients with acute respiratory failure requiring invasive ventilation in 22 hospitals in the Netherlands in the first 3 months of the international outbreak. The study protocol was approved by the local institutional review board of Amsterdam University Medical Center (location 'AMC') and registered at Clinicaltrials.gov (NCT04346342). The institutional review board waived the requirement for written informed consent at the participating sites. The original study protocol was pre-published elsewhere [11]. The proposed plan and statistical analysis of the current analysis were approved by the Core Steering Committee and published with the website of PRoVENT-COVID before data acquisition [12]. The protocol was revised to address the unanticipated severely zero-inflated distribution of ventilator-free days during the initial data acquisition (Supplementary Figure 1, Additional File 1). This analysis adheres to the Strengthening the Reporting of Observational Studies in Epidemiology statement.

\section{Selection criteria}

Invasively ventilated adult patients who met the criteria for ARDS using the Berlin definition [13] and who had real-time polymerase chain reaction confirmed COVID-19 admitted to one of the participating ICUs were eligible for participation. The original PRoVENT-COVID study protocol had no exclusion criteria; however, for the current analysis, we excluded patients if they were not invasively ventilated beyond the first 4 calendar days and patients who were transferred within the first 4 days of ventilation from or to another ICU that did not participate in the PRoVENT-COVID study.

\section{Exposure}

The primary exposure of interest was the cumulative fluid balance during the first 4 calendar days of invasive ventilation, calculated by total fluid input minus total fluid output on a certain day of ICU 
admission.

\section{Outcomes}

The primary outcome was successful liberation from invasive ventilation at 28 days, defined as the timepoint at which a patient was alive and extubated. Secondary outcomes were acute kidney injury (according to a modified Kidney Disease Improving Global Outcomes definition) [14], the use of renal replacement therapy, duration of invasive ventilation in survivors and non-survivors, ICU and hospital length of stay in survivors and non-survivors, and 28-day mortality.

\section{Statistical analyses}

Descriptive statistics were used to describe the study population and fluid management parameters. Data are presented as numbers and percentages for categorical variables and as means and standard deviation or median and interquartile range according to distribution. Where appropriate, statistical variability is expressed by $95 \%$ confidence intervals.

Using a mixed-effects model, we first examined the crude association between cumulative fluid balance and successful liberation from ventilation at day 28 with successful liberation of ventilation as a dependent variable, fluid balance as (fixed effect) as an independent variable, and hospital as a random intercept effect. Cumulative fluid balance from day 0 through day 1 was grouped as day 1 , and the subsequent days were labelled as day 2 , and day 3 . Cumulative fluid balance during the first 4 calendar days is referred to hereafter as cumulative fluid balance at day 3 . To examine potential nonlinearity in the association, the cumulative fluid balance was entered as a restricted cubic spline function with 3 knots distributed equally along the density. The complexity of the spline function was reduced in a stepwise fashion until minimization of the Akaike information criterion (AIC) (Supplementary Figure 2, Additional File 1). The exposure (cumulative fluid balance at day 3 ) was divided into tertiles to facilitate interpretation.

The association between cumulative fluid balance at day 3 and the probability of successful liberation from invasive ventilation was then adjusted for possible confounders by including these variables as (fixed effect) covariates in the mixed effects model. The set of predefined adjustment variables included the following: sex, age, body mass index, serum creatinine, use of vasopressors (norepinephrine dose), tidal volume, arterial $\mathrm{pH}$, positive end-expiratory pressure, partial pressure of oxygen to fraction inspired oxygen, dynamic respiratory system compliance and arterial lactate, all measured on the day of intubation.

Conditional on the assumption that the data were missing at random and the severity illness scores were collected differently by hospitals, before imputation, the percentage of missing data in the severity of illness scores in the first 3 days were assessed and addressed by a multi-level multiple imputation method. We imputed 20 datasets using multiple imputation by chained equations [15]. No exposure (day 3 fluid balance) or outcomes (survival and duration of ventilation) were imputed. All models described in 
the 'statistical analysis' section were reproduced in the 20 databases after multiple imputations and the results were pooled. We considered statistical significance at $P \leq 0.05$.

No formal statistical power calculation was conducted before the study. The sample size was solely based on the available data from the PRoVENT-COVID database.

\section{Sensitivity analyses}

To assess the robustness of the findings toward the missing data and imputation method, we refit the main regression model (i.e., the marginal effect of day 3 fluid balance on the hazard of successful liberation from invasive ventilation) on cases with complete data only. To retain the largest possible sample size, only covariates that were significantly associated with the outcome in the main model were included in the sensitivity model.

We also estimated the main effect of different classes of ARDS severity by including this variable in the adjusted mixed effects model.

\section{Results}

\section{Patient population and characteristics}

We identified 687 invasively ventilated COVID-19 and ARDS patients admitted to ICUs between March 1 , 2020, and June 1, 2020. The study flow chart is summarized in Figure 1. Table 1 describes the baseline and ventilation characteristics of our study participants. The most prevalent comorbidities were hypertension and diabetes. -

\section{Cumulative fluid balance distribution}

The distribution of cumulative fluid balance at day 3 was evaluated for the overall cohort (Supplementary Figure 3, Additional File 1). Complete exposure (fluid balance) data were available for 676 subjects on day $0 ; 673$ subjects on day $1 ; 661$ subjects on day 2 ; and 650 subjects on day 3 . Patients were divided into tertiles by day 3 cumulative fluid balance: highest, intermediate and lowest tertile groups had a median cumulative fluid balance of 1.98 liters [range 1.27-7.72 liter], 0.78 liter [0.26-1.27 liter] and -0.35 liter [-6.52-0.26 liter], respectively. Patients in the higher cumulative fluid balance group had a higher prevalence of chronic hypertension; worse baseline Simplified Acute Physiology Score, and higher lung compliance (Table 1).

\section{Association of cumulative fluid balance with outcomes}

The association between day 3 cumulative fluid balance and the hazard of successful liberation from ventilation was most parsimoniously characterized by a 0 -spline (linear) survival model. Models with 3-, 2-, or 1-knot-restricted cubic splines for cumulative fluid balance had higher AICs (i.e., no better fit) (Supplementary Figure 2, Additional File 1). 
The resulting association between cumulative fluid balance at day 3 and the probability of successful liberation from invasive ventilation is shown in Figure 2. In unadjusted analysis, there was a significant association between higher cumulative fluid balance at day 3 and a lower probability of successful liberation from ventilation, with a hazard ratio per liter fluid balance of $0.86(95 \% \mathrm{Cl} 0.78-0.96, P=0.005)$. After adjusting for a predefined set of possible confounding variables (listed in Supplementary Table 1, Additional File 1), exposure to higher cumulative fluid balance at day 3 remained significantly associated with lower probability of successful liberation of invasive ventilation. The adjusted hazard ratio for successful liberation from invasive ventilation associated with each liter increase in cumulative fluid balance was $0.86(95 \% \mathrm{Cl} 0.77-0.95, P=0.0047)$.

\section{Secondary outcomes and sensitivity analysis}

The secondary outcomes are summarized in Table 2. Length of ICU stay, length of hospital stays, and duration of intubation were significantly shorter for surviving patients who were in the lower tertile of cumulative fluid balance. Other outcomes did not differ significantly between fluid balance tertiles.

Two sensitivity analyses were performed. First, the robustness of our findings was assessed toward the missing data and imputation method (Supplementary Table 2, Additional File 1). In the complete-casesonly model, the sample size was reduced to 461 patients; the estimated association between day 3 cumulative fluid balance and successful liberation of invasive ventilation was similar to the estimation with imputed data. The hazard ratio per liter fluid balance was consistent with the primary analysis, 0.86 $(95 \% \mathrm{Cl} 0.76-0.98, P=0.0247)$.

Second, the models were re-analyzed according to ARDS severity, considering a possible interaction between the severity of ARDS and fluid balance. The interaction between ARDS severity and day 3 cumulative fluid balance did not improve the model fit (AIC of interaction model 4336 vs. 4335 for reduced model), indicating that there was no significant interaction between day 3 cumulative fluid balance and ARDS severity on the association with successful liberation from invasive ventilation (Figure 3).

\section{Discussion}

The main findings of this multicentric observational study of COVID-19 and ARDS patients include the following: (1) a higher day 3 cumulative fluid balance was associated with a lower probability of successful liberation from invasive ventilation; (2) these results remained consistent even after adjustment for potential predefined confounding factors and sensitivity analyses; and (3) reduction in duration of invasive ventilation, hospital and ICU length of stay was noted in patients who had lower cumulative fluid balance.

Our results corroborated the growing evidence suggesting the unfavorable effect of higher positive fluid balance on outcomes in critically ill patients [16-19]. However, compared to these studies, there are also some notable differences in our study. We specifically evaluated the exposure of cumulative fluid balance 
in COVID-19 and ARDS patients on the ventilation liberation irrespective of prior spontaneous breathing trials. Cumulative fluid balance was calculated from hospital admission until day 3 , whereas in other studies, it was calculated differently. Despite these differences, a signal of potential harm with excessive cumulative fluid balance and weaning outcomes was consistently observed.

Evidence emanating from large trials of ARDS patients has led to an overall practice change that resulted in relatively less aggressive initial fluid management. In 2006, the Fluids and Catheters Treatment Trial reported a causal effect between positive fluid balance and duration of ventilation in ARDS patients [8]. The authors found that the conservative group had a shorter ventilation duration than the liberal-strategy group without an increase in non-pulmonary organ failure. Another study, performed by the ARDSnet, showed that negative cumulative fluid balance was significantly associated with more ventilator freedays and lower mortality than positive cumulative fluid balance [20]. A limitation of using 'ventilator-free days' in these reports is that a more frequently occurring component of the composite (such as survival or duration of ventilation) presumably drives the effect estimates and could influence the results, even stronger when the components are oppositely affected by the exposure [1, 21]. Our rationale for using 'ventilator-free days' was to compare our analysis to previously conducted studies readily; one of the challenges was disentangling the contribution of 'zero-inflated distribution' in ventilator-free days.

However, it is possible that a greater-than-expected number of non-survivors had died within 24-hours of initiation of ventilation, and this could presumably drive the mean difference towards null. Or, because of unknown factors, certain patients might not have been able to present values other than zero.

Nevertheless, we addressed it by restricting our primary outcome to only 'successful ventilation liberation' instead of 'ventilator-free days'; however, our analysis suffered from model selection bias.

Several mechanisms may explain the association of higher cumulative fluid balance and decreased odds of ventilation liberation. Higher positive fluid balance increases the extravascular lung water, and inattention to fluid overload may inadvertently promote counterproductive outcomes, such as pulmonary dysvasoregulation and alveolar edema, contributing to weaning failure. This risk is particularly high among patients with COVID-19 and ARDS because of relatively higher extravascular lung water and pulmonary vascular permeability indices, in distinct contrast to non-COVID ARDS [22]. Furthermore, alveolar fluid clearance is perhaps slow or even impaired in ARDS pathophysiology. The combined processes of high vascular permeability and impaired alveolar fluid clearance may therefore rapidly worsen the alveolar edema - even with a slight increase in intravascular volume [23, 24]. Consistent with this view, we showed that even a one-liter increase in the dose of cumulative fluid balance might significantly decrease ventilation liberation odds. For example, about $14 \%$ (hazard ratio of 0.86 ) lower rate of successful ventilation liberation was noted with each liter of fluid addition to cumulative fluid balance - implying a dose-response relationship. Importantly, our results do not imply a causal relationship, as causality can only be identified in a randomized trial; however, given the strength of association between cumulative fluid balance and weaning outcome, a well-designed trial seems well justified. Taken together with the previous research, our results indicate a possible beneficial effect of restrictive fluid management in invasively ventilated COVID-19 and ARDS patients. 
Higher cumulative fluid balance has also been suggested in previous studies of non-COVID-19 ARDS patients to be potentially associated with worsened outcomes, such as acute kidney injury and decreased survival [25]. In our study, no association was observed in the lower cumulative fluid balance group with respect to our secondary endpoints, such as acute kidney injury, the requirement of renal replacement therapy, and mortality, with the caveat that our analysis was too small to evaluate these endpoints, and therefore, should be considered as only hypothesis-generating for future investigations.

The strengths of our study include the size of the multicenter cohort of 22 hospitals that comprised both academic and non-academic institutions, increasing the generalizability of our results. We took careful steps to prevent selection bias that could have been caused by patients who were transferred from other hospitals. Also, trained study coordinators performed careful data collection, and a pre-specified statistical analysis plan was prepared before data acquisition.

Our study is subject to several limitations. Although we adjusted for potential prespecified confounders, our results may be biased by unmeasured confounders. Our analysis did not adjust for imbalances such as hypertension and baseline Simplified Acute Physiology Score in the higher cumulative fluid balance group. Furthermore, sensitivity analysis detected no heterogeneous effect. Multiple challenges to research existed during the pandemic that may have affected the clinical outcomes for the included patients, such as organizational issues to utilize resources to prevent future upheavals. Included data were derived from 22 collaborative hospitals that exhibited variation in practice; for example, weaning did not occur with a mandatory protocol, and healthcare provider-related bias could have affected the weaning outcomes. While the percentage of missing values was low, missing data-related bias due to the adoption of different severity illness scores by various centers were thoroughly handled by imputation approaches such as last observation carried forward and robust evaluation tools.

\section{Conclusions}

This multicenter study of invasively ventilated COVID-19 and ARDS patients suggest a strong association between higher day 3 cumulative fluid balance and the duration of ventilation, even after adjusting for a predefined set of possible confounding variables. Nevertheless, randomized clinical trials are required to confirm our findings. To the extent that higher positive fluid balance suggests harm and influences weaning outcomes, maintenance of restrictive cumulative fluid balance may improve weaning outcomes in invasively ventilated COVID-19 and ARDS patients.

\section{Abbreviations}

AIC: Akaike information criterion

ARDS: acute respiratory distress syndrome

COVID-19: coronavirus disease 2019 
PRoVENT-COVID: PRactice of VENTilation in COVID-19 patients

\section{Declarations}

Ethics approval and consent to participate: This study was performed according to the principles of the Declaration of Helsinki (revision Fortaleza, Brazil, October 2013). Approval was granted by the local Institutional Review Board of the Amsterdam University Medical Centers, location 'AMC', on April 7, 2020, No. W20_157 \# 20.171. 04-2020. Participating centers submitted the study protocol to their local institutional review board for judgment of feasibility and the requirement of consent was waived by the institutional review board of participating centers.

Consent for publication: Not applicable.

Availability of data and materials: The datasets used and/or analyzed during the current study are available from the authors on reasonable request.

Competing interests: All authors declare no competing interests related to the submitted work.

Funding: Support was solely provided from institutional and/or individual center departmental sources.

Authors' contributions: All authors contributed to the study conception and design. The first draft of the manuscript was written by [SA], [HD], [MJS], [PRT] and all authors commented on previous versions of the manuscript. Material preparation, data collection and analysis were performed by [HD], [SA], [FP], [MJS], [PRT]. All authors read and approved the final manuscript.

Acknowledgements: ${ }^{*}$ PRoVENT-COVID Collaborative Group. Investigators: (in alphabetic order): S. Ahuja ${ }^{1}$; J.P. van Akkeren'; A.G. Algera ${ }^{3}$; C.K. Algoe ${ }^{3}$; R.B. van Amstel ${ }^{3}$; A. Artigas ${ }^{4}$; O.L. Baur ${ }^{3}$; P. van de Berg'; A.E. van den Berg ${ }^{6}$; D.C.J.J. Bergmans ${ }^{7}$; D.I. van den Bersselaar ${ }^{3}$; F.A. Bertens ${ }^{3}$; A.J.G.H. Bindels ${ }^{5}$; M.M. de Boer $^{3}$; S. den Boer ${ }^{8}$; L.S. Boers ${ }^{3}$; M. Bogerd ${ }^{3}$; L.D.J. Bos ${ }^{3}$; M. Botta ${ }^{3}$; J.S. Breel ${ }^{9}$; H. de Bruin ${ }^{3}$; S. de Bruin ${ }^{3}$; C.L. Bruna ${ }^{3}$; L.A. Buiteman-Kruizinga ${ }^{10}$; O. L. Cremer $^{11}$; R.M. Determann ${ }^{12}$; W. Dieperink ${ }^{13}$; D.A. Dongelmans $^{3}$; H.S. Franke ${ }^{13}$; M.S. Galek-Aldridge ${ }^{3}$; M.J. de Graaff ${ }^{14}$; L.A. Hagens ${ }^{3}$; J.J. Haringman ${ }^{16}$; S.T. van der Heide ${ }^{3}$; P.L.J. van der Heiden ${ }^{10}$; N.F.L. Heijnen ${ }^{15}$; S.J.P. Hiel ${ }^{2}$; L.L. Hoeijmakers ${ }^{3}$; L. Hol ${ }^{3,9}$; M.W. Hollmann"; M.E. Hoogendoorn ${ }^{16}$; J. Horn ${ }^{3}$; R. van der Horst ${ }^{17}$; E.L.K. le ${ }^{3}$; D. Ivanov ${ }^{3}$; N.P. Juffermans ${ }^{12}$; E. Kho $^{3}$; E.S. de Klerk ${ }^{9}$; A.W.M.M. Koopman-van Gemert ${ }^{18}$; M. Koopmans ${ }^{12}$; S. Kucukcelebi ${ }^{3}$; M.A. Kuiper ${ }^{19}$; D.W. de Lange ${ }^{11}$; N. van Mourik ${ }^{3}$; S.G. Nijbroek ${ }^{3,9}$; M. Onrust ${ }^{13}$; E.A.N. Oostdijk ${ }^{20}$; F. Paulus ${ }^{3,21}$; C.J. Pennartz ${ }^{3}$; J. Pillay3,13; L. Pisani3; I.M. Purmer6; T.C.D. Rettig22; J.P. Roozeman³ ${ }^{3}$ M.T.U. Schuijt ${ }^{3}$; M.J. Schultz ${ }^{3,23,24}$; A. Serpa Neto ${ }^{25}$; M.E. Sleeswijk ${ }^{26}$; M.R. Smit'; P.E. Spronk ${ }^{27}$; W. Stilma3; A.C. Strang ${ }^{28}$; A.M. Tsonas $^{3}$; P.R. Tuinman ${ }^{29}$; C.M.A. Valk ${ }^{3}$; F.L. Veen-Schra ${ }^{16}$; L.I. Veldhuis ${ }^{3}$; P. van Velzen ${ }^{30}$; W.H. van der 
Ven $^{9}$; A.P.J. Vlaar ${ }^{3}$; P. van Vliet ${ }^{31}$; P.H.J. van der Voort ${ }^{13}$; L. van Welie ${ }^{32}$; H.J.F.T. Wesselink ${ }^{16} ;$ H.H. van der Wier-Lubbers $^{16}$; B. van Wijk ${ }^{3}$; T. Winters ${ }^{3}$; W.Y. Wong ${ }^{3}$; A.R.H. van Zanten ${ }^{32}$.

Institutional and Departmental Affiliations: ${ }^{1}$ Department of Anesthesiology, Pain Management \& Perioperative Medicine, Henry Ford Health System, Detroit, Michigan, United States; ${ }^{2}$ Department of Intensive Care, Maxima Medical Center, Eindhoven, The Netherlands; ${ }^{3}$ Department of Intensive Care, Amsterdam University Medical Centers, location 'Academic Medical Center', Amsterdam, The Netherlands; ${ }^{4}$ Critical Care Center, Sabadell Hospital, Sabadell, Spain; ${ }^{5}$ Department of Intensive Care, Catharina Hospital, Eindhoven, The Netherlands; ${ }^{6}$ Department of Intensive Care, Haga Hospital, the Hague, The Netherlands; ${ }^{7}$ Department of Intensive Care, Maastricht University Medical Center, Maastricht, The Netherlands; ${ }^{8}$ Department of Intensive Care, Spaarne Hospital, Haarlem, The Netherlands; ${ }^{9}$ Department of Anaesthesiology, Amsterdam University Medical Centers, location 'Academic Medical Center', Amsterdam, The Netherlands; ${ }^{10}$ Department of Intensive Care, Reinier de Graaf Hospital, Delft, The Netherlands; ${ }^{11}$ Department of Intensive Care, University Medical Center Utrecht, Utrecht, The Netherlands; ${ }^{12}$ Department of Intensive Care, OLVG Hospital, location East, Amsterdam, The Netherlands; ${ }^{13}$ Department of Intensive Care, University Medical Center Groningen, Groningen, The Netherlands; ${ }^{14}$ Department of Intensive Care, Sint Antonius Hospital, Nieuwegein, The Netherlands; ${ }^{15}$ Department of Intensive Care, Maastricht University Medical Center, Maastricht, The Netherlands; ${ }^{16}$ Department of Intensive Care, Isala Hospital, Zwolle, The Netherlands; ${ }^{17}$ Department of Intensive Care; Zuyderland Hospital, Heerlen and Sittard, The Netherlands; ${ }^{18}$ Department of Intensive Care ZGT Hospital, Almelo, The Netherlands; ${ }^{19}$ Department of Intensive Care Medical Center Leeuwarden, Leeuwarden, The Netherlands; ${ }^{20}$ Department of Intensive Care; Maasstad Hospital, Rotterdam, The Netherlands; ${ }^{21}$ ACHIEVE, Center of Applied Research Amsterdam University of Applied Sciences, Faculty of Health, Amsterdam, The Netherlands; ${ }^{22}$ Department of Intensive Care Amphia Hospital, Breda, The Netherlands; ${ }^{23}$ Mahidol-Oxford Tropical Medicine Research Unit (MORU), Mahidol University, Bangkok, Thailand; ${ }^{24}$ Nuffield Department of Medicine, University of Oxford, Oxford, United Kingdom; ${ }^{25}$ Department of Critical Care Medicine, Australian and New Zealand Intensive Care Research Center (ANZIC-RC), Monash University, Melbourne, Australia; ${ }^{26}$ Department of Intensive Care, FlevoHospital, Almere, The Netherlands; ${ }^{27}$ Department of Intensive Care, Gelre Hospital, Apeldoorn and Zutphen, The Netherlands:; ${ }^{28}$ Department of Intensive Care, Rijnstate Hospital, Arnhem, The Netherlands; ${ }^{29}$ Department of Intensive Care, Amsterdam University Medical Centers, location 'VU Medical Center', Amsterdam, The Netherlands; ${ }^{30}$ Department of Intensive Care, Dijklander Hospital, location Hoorn, Hoorn, The Netherlands;

${ }^{31}$ Department of Intensive Care Haaglanden Medical Center, location Westeinde, the Hague, The Netherlands; ${ }^{32}$ Department of Intensive Care Gelderse Vallei Hospital, Ede, The Netherlands.

\section{References}


1. Hasan SS, Capstick T, Ahmed R, Kow CS, Mazhar F, Merchant HA, Zaidi STR: Mortality in COVID-19 patients with acute respiratory distress syndrome and corticosteroids use: a systematic review and meta-analysis. Expert Rev Respir Med 2020, 14(11):1149-1163.

2. Madjid M, Safavi-Naeini P, Solomon SD, Vardeny O: Potential effects of coronaviruses on the cardiovascular system: a review. JAMA Cardiol 2020, 5(7):831-840.

3. Cha MH, Regueiro M, Sandhu DS: Gastrointestinal and hepatic manifestations of COVID-19: A comprehensive review. World J Gastroenterol 2020, 26(19):2323-2332.

4. Wang D, Hu B, Hu C, Zhu F, Liu X, Zhang J, Wang B, Xiang H, Cheng Z, Xiong Y et al: Clinical Characteristics of 138 Hospitalized Patients With 2019 Novel Coronavirus-Infected Pneumonia in Wuhan, China. Jama 2020, 323(11):1061-1069.

5. van Mourik N, Metske HA, Hofstra JJ, Binnekade JM, Geerts BF, Schultz MJ, Vlaar APJ: Cumulative fluid balance predicts mortality and increases time on mechanical ventilation in ARDS patients: an observational cohort study. PLoS One 2019, 14(10):e0224563.

6. Alhazzani W, Moller MH, Arabi YM, Loeb M, Gong MN, Fan E, Oczkowski S, Levy MM, Derde L, Dzierba A et al: Surviving Sepsis Campaign: guidelines on the management of critically ill adults with Coronavirus Disease 2019 (COVID-19). Intensive Care Med 2020, 46(5):854-887.

7. Silversides JA, Major E, Ferguson AJ, Mann EE, McAuley DF, Marshall JC, Blackwood B, Fan E: Conservative fluid management or deresuscitation for patients with sepsis or acute respiratory distress syndrome following the resuscitation phase of critical illness: a systematic review and metaanalysis. Intensive Care Med 2017, 43(2):155-170.

8. National Heart L, Blood Institute Acute Respiratory Distress Syndrome Clinical Trials N, Wiedemann HP, Wheeler AP, Bernard GR, Thompson BT, Hayden D, deBoisblanc B, Connors AF, Jr., Hite RD et al: Comparison of two fluid-management strategies in acute lung injury. N Engl J Med 2006, 354(24):2564-2575.

9. Sakr Y, Rubatto Birri PN, Kotfis K, Nanchal R, Shah B, Kluge S, Schroeder ME, Marshall JC, Vincent JL, Intensive Care Over Nations I: Higher fluid balance increases the risk of death from sepsis: results from a large international audit. Crit Care Med 2017, 45(3):386-394.

10. Finfer S, Myburgh J, Bellomo R: Intravenous fluid therapy in critically ill adults. Nat Rev Nephro/2018, 14(9):541-557.

11. Boers NS, Botta M, Tsonas AM, Algera AG, Pillay J, Dongelmans DA, Horn J, Vlaar APJ, Hollmann MW, Bos LDJ et al: PRactice of VENTilation in Patients with Novel Coronavirus Disease (PRoVENTCOVID): rationale and protocol for a national multicenter observational study in the Netherlands. Ann Transl Med 2020, 8(19):1251.

12. PRactice of VENTilation in Patients with Coronavirus Disease 2019 (PRoVENT-COVID) - rationale, study protocol and statistical analysis plans for a national multicenter observational study in the Netherlands [https://sites.google.com/view/provent-covid/]

13. Force ADT, Ranieri VM, Rubenfeld GD, Thompson BT, Ferguson ND, Caldwell E, Fan E, Camporota L, Slutsky AS: Acute respiratory distress syndrome: the Berlin Definition. JAMA 2012, 307(23):2526- 
2533.

14. Selby NM, Hill R, Fluck RJ, Programme NHSETKA: Standardizing the early identification of acute kidney injury: the NHS England national Patient Safety Alert. Nephron 2015, 131(2):113-117.

15. van Buuren S, Groothuis-Oudshoorn K: mice: Multivariate Imputation by Chained Equations in R. $J$ Stat Softw 2011, 45(3):1 - 67.

16. Upadya A, Tilluckdharry L, Muralidharan V, Amoateng-Adjepong Y, Manthous CA: Fluid balance and weaning outcomes. Intensive Care Med 2005, 31(12):1643-1647.

17. Maezawa S, Kudo D, Miyagawa N, Yamanouchi S, Kushimoto S: Association of body weight change and fluid balance with extubation failure in intensive care unit patients: a single-center observational study. J Intensive Care Med 2021, 36(2):175-181.

18. Frutos-Vivar F, Ferguson ND, Esteban A, Epstein SK, Arabi Y, Apezteguia C, Gonzalez M, Hill NS, Nava $S, D$ 'Empaire $\mathrm{G}$ et al: Risk factors for extubation failure in patients following a successful spontaneous breathing trial. Chest 2006, 130(6):1664-1671.

19. Yoo MS, Zhu S, Lu Y, Greene JD, Hammer HL, Iberti CT, Nemazie S, Ananias MP, McCarthy CM, O'Malley RM et al: Association of Positive Fluid Balance at Discharge After Sepsis Management With 30-Day Readmission. JAMA network open 2021, 4(6):e216105-e216105.

20. Rosenberg AL, Dechert RE, Park PK, Bartlett RH, Network NNA: Review of a large clinical series: association of cumulative fluid balance on outcome in acute lung injury: a retrospective review of the ARDSnet tidal volume study cohort. J Intensive Care Med 2009, 24(1):35-46.

21. Yehya N, Harhay MO, Curley MAQ, Schoenfeld DA, Reeder RW: Reappraisal of ventilator-free days in critical care research. Am J Respir Crit Care Med 2019, 200(7):828-836.

22. Shi R, Lai C, Teboul JL, Dres M, Moretto F, De Vita N, Pham T, Bonny V, Mayaux J, Vaschetto R et al: COVID-19 ARDS is characterized by higher extravascular lung water than non-COVID-19 ARDS: the PiCCOVID study. Crit Care 2021, 25(1):186.

23. Ware LB, Matthay MA: Alveolar fluid clearance is impaired in the majority of patients with acute lung injury and the acute respiratory distress syndrome. Am J Respir Crit Care Med 2001, 163(6):13761383.

24. Semler MW, Wheeler AP, Thompson BT, Bernard GR, Wiedemann HP, Rice TW, National Institutes of Health National Heart, Lung, and Blood Institute Acute Respiratory Distress Syndrome Network: Impact of initial central venous pressure on outcomes of conservative versus liberal fluid management in acute respiratory distress syndrome. Crit Care Med 2016, 44(4):782-789.

25. Schuller D, Mitchell JP, Calandrino FS, Schuster DP: Fluid balance during pulmonary edema. Is fluid gain a marker or a cause of poor outcome?Chest 1991, 100(4):1068-1075.

\section{Tables}

Table 1: Baseline characteristics and clinical outcome of the included patient cohort 


\begin{tabular}{|c|c|c|c|c|}
\hline & Lower & Intermediate & Higher & $\begin{array}{l}\mathrm{P}- \\
\text { value }\end{array}$ \\
\hline $\begin{array}{l}\text { Overall cohort, } \\
\mathrm{N}=650, \mathrm{~N}(\%)\end{array}$ & $215(100.0)$ & $220(100.0)$ & $215(100.0)$ & \\
\hline \multicolumn{5}{|c|}{ Demographic characteristics } \\
\hline Gender, male, N (\%) & $145(67.8)$ & $160(72.7)$ & $161(74.9)$ & 0.243 \\
\hline Age, years & $65.00[57.00,71.00]$ & $\begin{array}{l}66.50[58.75 \\
72.25]\end{array}$ & $66.00[59.00,73.00]$ & 0.289 \\
\hline Weight, kg & $85.00[75.00,94.60]$ & $\begin{array}{l}86.00[79.00 \\
96.00]\end{array}$ & $88.40[80.00,98.30]$ & 0.023 \\
\hline Height, cm & $\begin{array}{l}175.00[168.00 \\
180.00]\end{array}$ & $\begin{array}{l}175.00[169.00, \\
182.00]\end{array}$ & $\begin{array}{l}176.00[170.00 \\
182.50]\end{array}$ & 0.341 \\
\hline $\begin{array}{l}\text { Body mass index, } \\
\mathrm{kg} / \mathrm{m} 2\end{array}$ & $27.44[25.06,30.48]$ & $\begin{array}{l}27.99[25.71 \\
30.47]\end{array}$ & $28.34[26.02,31.62]$ & 0.081 \\
\hline \multicolumn{5}{|l|}{$\begin{array}{l}\text { Comorbid conditions } \\
(\%)\end{array}$} \\
\hline Comorbid. None & $42(19.6)$ & $55(25.0)$ & $59(27.4)$ & 0.153 \\
\hline Hypertension & $83(38.8)$ & $58(26.4)$ & $67(31.2)$ & 0.02 \\
\hline Heart failure & $11(5.1)$ & $7(3.2)$ & $11(5.1)$ & 0.524 \\
\hline Diabetes mellitus & $54(25.2)$ & $34(15.5)$ & $53(24.7)$ & 0.021 \\
\hline $\begin{array}{l}\text { Chronic kidney } \\
\text { disease }\end{array}$ & $10(4.7)$ & $5(2.3)$ & $10(4.7)$ & 0.326 \\
\hline Liver cirrhosis & $0(0.0)$ & $1(0.5)$ & $1(0.5)$ & 0.61 \\
\hline COPD & $15(7.0)$ & $18(8.2)$ & $17(7.9)$ & 0.892 \\
\hline $\begin{array}{l}\text { Hematological } \\
\text { malignancy }\end{array}$ & $3(1.4)$ & $4(1.8)$ & $3(1.4)$ & 0.919 \\
\hline $\begin{array}{l}\text { Solid tumor } \\
\text { malignancy }\end{array}$ & $7(3.3)$ & $8(3.6)$ & $3(1.4)$ & 0.314 \\
\hline $\begin{array}{l}\text { Neuromuscular } \\
\text { disease }\end{array}$ & $1(0.5)$ & $1(0.5)$ & $2(0.9)$ & 0.772 \\
\hline $\begin{array}{l}\text { Immunosuppression } \\
\text { use }\end{array}$ & $7(3.3)$ & $6(2.7)$ & $7(3.3)$ & 0.932 \\
\hline Other comorbidities & $108(50.5)$ & $108(49.1)$ & $99(46.0)$ & 0.644 \\
\hline $\begin{array}{l}\text { Unknown } \\
\text { comorbidities }\end{array}$ & $1(0.5)$ & $1(0.5)$ & $0(0.0)$ & 0.608 \\
\hline Creatinine $(\mu \mathrm{mol} / \mathrm{L})$ & $74.00[61.00,93.00]$ & $73.00[57.50$ & $79.00[64.00$ & 0.079 \\
\hline
\end{tabular}




\section{Day 0 variables (median [interquartile range])}

\begin{tabular}{|c|c|c|c|c|}
\hline Tidal volume (set) & $\begin{array}{l}450.00[400.00 \\
485.00]\end{array}$ & $\begin{array}{l}400.00[400.00 \\
420.00]\end{array}$ & $\begin{array}{l}400.00[380.00 \\
440.00]\end{array}$ & 0.271 \\
\hline $\begin{array}{l}\text { Tidal volume } \\
\text { (expired) }\end{array}$ & $\begin{array}{l}434.50[389.50, \\
476.25]\end{array}$ & $\begin{array}{l}425.50[379.25 \\
477.50]\end{array}$ & $\begin{array}{l}450.00[400.00 \\
508.00]\end{array}$ & 0.007 \\
\hline PEEP & $12.00[10.00,15.00]$ & $\begin{array}{l}12.00[10.00 \\
14.00]\end{array}$ & $12.00[10.00,15.00]$ & 0.125 \\
\hline Peak pressures & $28.00[24.00,31.00]$ & $\begin{array}{l}26.00[24.00 \\
30.00]\end{array}$ & $27.00[24.00,30.00]$ & 0.019 \\
\hline Fi02 & $0.70[0.60,0.90]$ & $0.65[0.58,0.80]$ & $0.70[0.60,0.80]$ & 0.105 \\
\hline $\mathrm{pH}$ & $7.36[7.31,7.41]$ & $7.37[7.31,7.43]$ & $7.36[7.29,7.41]$ & 0.428 \\
\hline $\mathrm{PaO} 2$ & $10.80[9.50,12.66]$ & $10.80[9.00,13.15]$ & $10.90[9.50,13.50]$ & 0.682 \\
\hline Ventilator free days & $3.00[0.00,9.00]$ & $4.00[0.00,11.25]$ & $0.00[0.00,12.00]$ & 0.286 \\
\hline $\mathrm{PaO}_{2} / \mathrm{FiO}_{2}$ ratio & $\begin{array}{l}120.00 \\
{[96.59,153.92]}\end{array}$ & $\begin{array}{l}121.88[92.78 \\
176.87]\end{array}$ & $\begin{array}{l}130.03[93.33, \\
171.25]\end{array}$ & 0.126 \\
\hline $\begin{array}{l}\text { Dynamic compliance } \\
\text { (Cdyn) }\end{array}$ & $28.62[22.79,34.62]$ & $\begin{array}{l}30.36[23.79 \\
37.51]\end{array}$ & $31.38[26.10,40.77]$ & $<0.001$ \\
\hline Lactate & $1.2[0.97,1.50]$ & $1.20[0.90,1.50]$ & $1.10[0.90,1.40]$ & 0.084 \\
\hline SAPS & $32.00[27.00,38.00]$ & $\begin{array}{l}32.00[26.50 \\
39.50]\end{array}$ & $38.00[32.00,45.50]$ & 0.001 \\
\hline APACHE II & $16.00[12.00,22.00]$ & $\begin{array}{l}17.00[11.50, \\
22.00]\end{array}$ & $16.00[13.25,19.75]$ & 0.979 \\
\hline APACHE IV & $51.00[43.00,65.25]$ & $\begin{array}{l}56.50[44.00 \\
65.00]\end{array}$ & $59.00[46.00,72.50]$ & 0.083 \\
\hline SOFA & $7.00[6.00,10.00]$ & $7.00[6.00,9.00]$ & $8.00[6.00,9.00]$ & 0.489 \\
\hline Creatinine $(\mu \mathrm{mol} / \mathrm{L})$ & $70.00[57.00,87.00]$ & $\begin{array}{l}73.00[57.50, \\
93.50]\end{array}$ & $75.00[63.00,99.50]$ & 0.055 \\
\hline Urine (ml) & $\begin{array}{l}780.00[450.00 \\
1220.00]\end{array}$ & $\begin{array}{l}825.00[460.00 \\
1240.00]\end{array}$ & $\begin{array}{l}725.00[398.75 \\
1130.00]\end{array}$ & 0.152 \\
\hline Fluid balance $(\mathrm{ml})$ & $\begin{array}{l}698.00[-34.00 \\
1598.00]\end{array}$ & $\begin{array}{l}556.00[37.50 \\
1283.10]\end{array}$ & $\begin{array}{l}826.00[212.00 \\
1762.00]\end{array}$ & 0.016 \\
\hline \multicolumn{5}{|l|}{ Day 1 variables } \\
\hline SOFA & $7.00[6.00,9.00]$ & $7.00[5.25,9.00]$ & $7.00[6.00,9.00]$ & 0.373 \\
\hline Creatinine $(\mu \mathrm{mol} / \mathrm{L})$ & $\begin{array}{l}83.00[66.00 \\
123.00]\end{array}$ & $\begin{array}{l}80.00[63.00 \\
111.00]\end{array}$ & $\begin{array}{l}86.00[68.00 \\
121.75]\end{array}$ & 0.171 \\
\hline
\end{tabular}




\begin{tabular}{|c|c|c|c|c|}
\hline Urine $(\mathrm{ml})$ & $\begin{array}{l}1125.00[778.75, \\
1588.25]\end{array}$ & $\begin{array}{l}1062.50[805.00 \\
1446.25]\end{array}$ & $1202.02(697.48)$ & 0.759 \\
\hline Fluid balance (ml) & $\begin{array}{l}1460.90[649.70 \\
21621.00]\end{array}$ & $\begin{array}{l}1507.50 \text { [824.12, } \\
2116.50]\end{array}$ & $\begin{array}{l}\text { 1918.00 [1173.35, } \\
2867.45]\end{array}$ & $<0.001$ \\
\hline $\begin{array}{l}\text { Norepinephrine, } \\
\text { mg/24-hour }\end{array}$ & $\begin{array}{l}11.98[3.60 \\
9216.00]\end{array}$ & $8.99[3.46,21.56]$ & $12.21[6.00,41.40]$ & 0.021 \\
\hline \multicolumn{5}{|l|}{ Day 2 variables } \\
\hline SOFA & $7.00[6.00,11.00]$ & $7.00[5.00,9.00]$ & $7.00[6.00,9.00]$ & 0.232 \\
\hline Creatinine $(\mu \mathrm{mol} / \mathrm{L})$ & $\begin{array}{l}86.00[64.00 \\
131.00]\end{array}$ & $\begin{array}{l}83.00[63.75 \\
124.25]\end{array}$ & $\begin{array}{l}87.00[70.00 \\
143.00]\end{array}$ & 0.215 \\
\hline Urine (ml) & $\begin{array}{l}1407.50[990.00, \\
2071.25]\end{array}$ & $\begin{array}{l}1095.00 \text { [833.75, } \\
1437.75]\end{array}$ & 1121.19 (696.37) & $<0.001$ \\
\hline Fluid balance (ml) & $\begin{array}{l}773.50[0.25 \\
1398.75]\end{array}$ & $\begin{array}{l}1157.00[615.00 \\
1807.25]\end{array}$ & $\begin{array}{l}1782.00[1219.50 \\
2530.00]\end{array}$ & $<0.001$ \\
\hline $\begin{array}{l}\text { Norepinephrine, } \\
\text { mg/24-hour }\end{array}$ & $\begin{array}{l}12.40[3.74 \\
9216.00]\end{array}$ & $7.92[3.33,26.64]$ & $14.65[5.11,41.00]$ & 0.017 \\
\hline \multicolumn{5}{|l|}{ Day 3 variables } \\
\hline SOFA & $7.00[6.00,11.00]$ & $7.00[5.00,9.00]$ & $7.00[6.00,9.00]$ & 0.56 \\
\hline Creatinine $(\mu \mathrm{mol} / \mathrm{L})$ & $\begin{array}{l}85.00[62.00 \\
129.00]\end{array}$ & $\begin{array}{l}79.50[61.00 \\
127.50]\end{array}$ & $\begin{array}{l}86.00[68.00 \\
171.00]\end{array}$ & 0.07 \\
\hline Urine (ml) & $\begin{array}{l}2112.50[1511.25, \\
2735.00]\end{array}$ & $\begin{array}{l}1280.00[867.50 \\
1722.50]\end{array}$ & $1030.17(641.13)$ & $<0.001$ \\
\hline Fluid balance (ml) & $\begin{array}{l}-344.75[-751.55, \\
1.72]\end{array}$ & $\begin{array}{l}780.00[499.72 \\
1013.75]\end{array}$ & $\begin{array}{l}\text { 1988.00 [1638.30, } \\
2397.00]\end{array}$ & $<0.001$ \\
\hline $\begin{array}{l}\text { Norepinephrine, } \\
\text { mg/24-hour }\end{array}$ & $8.75[2.70,9216.00]$ & $6.90[2.45,19.74]$ & $13.75[5.18,58.13]$ & 0.003 \\
\hline
\end{tabular}

APACHE, acute physiology assessment and chronic health evaluation; COPD, chronic obstructive pulmonary disease; $\mathrm{FiO} 2$, fraction of inspired oxygen; $\mathrm{PaO} 2$, arterial partial pressure of oxygen; $\mathrm{PEEP}$, positive end expiratory pressure; SAPS, simplified acute physiology score; SOFA, sequential organ failure assessment.

Data are shown as median $\left[25^{\text {th }}\right.$ percentile, $75^{\text {th }}$ percentile] or $\mathrm{N}(\%)$. Non-normal values are displayed as median $\left[25^{\text {th }}\right.$ percentile, $75^{\text {th }}$ percentile] and those with normal distribution are represented as mean (standard deviation).

Table 2: Patient centered endpoints stratified by tertiles. 


\begin{tabular}{|c|c|c|c|c|}
\hline & Lower & Intermediate & Higher & $\begin{array}{l}\mathrm{P}- \\
\text { value }\end{array}$ \\
\hline Overall cohort, $N=650, N(\%)$ & $215(100.0)$ & $220(100.0)$ & $215(100.0)$ & \\
\hline Acute kidney injury & $110(52.1)$ & $102(46.6)$ & $122(56.7)$ & 0.105 \\
\hline Requiring RRT & $63(29.4)$ & $58(26.4)$ & $67(31.2)$ & 0.535 \\
\hline $\mathrm{CVVH} / \mathrm{CVVHDF}$ & $46(21.5)$ & $43(19.5)$ & $55(25.6)$ & 0.304 \\
\hline Hemodialysis & $3(1.4)$ & $7(3.2)$ & $7(3.3)$ & 0.395 \\
\hline Peritoneal dialysis & $0(0.0)$ & $0(0.0)$ & $1(0.5)$ & 0.364 \\
\hline 28-day mortality & $62(29.0)$ & $61(27.7)$ & $78(36.3)$ & 0.116 \\
\hline $\begin{array}{l}\text { Duration of intubation at 28- } \\
\text { day }\end{array}$ & $\begin{array}{l}16.00[6.00 \\
28.00]\end{array}$ & $\begin{array}{l}21.00[8.75 \\
28.00]\end{array}$ & $\begin{array}{l}28.00[12.00 \\
28.00]\end{array}$ & 0.001 \\
\hline Survivors & $8.00[4.00,18.25]$ & $\begin{array}{l}12.00[6.00 \\
26.00]\end{array}$ & $\begin{array}{l}14.00[7.00 \\
28.00]\end{array}$ & $<0.001$ \\
\hline Non-survivors & $6.50[3.00,13.75]$ & $\begin{array}{l}10.00[2.00 \\
14.00]\end{array}$ & $5.50[2.00,11.00]$ & 0.228 \\
\hline $\begin{array}{l}\text { Intensive care unit length of } \\
\text { stay }\end{array}$ & $\begin{array}{l}14.00[9.00 \\
22.75]\end{array}$ & $\begin{array}{l}18.00[11.00 \\
28.00]\end{array}$ & $\begin{array}{l}17.00[9.50 \\
29.00]\end{array}$ & 0.019 \\
\hline Survivors & $\begin{array}{l}15.00[9.75 \\
27.25]\end{array}$ & $\begin{array}{l}20.00[13.00 \\
34.00]\end{array}$ & $\begin{array}{l}23.00[14.00 \\
37.00]\end{array}$ & $<0.001$ \\
\hline Non-survivors & $\begin{array}{l}10.50[7.00 \\
17.75]\end{array}$ & $\begin{array}{l}14.00[6.00 \\
18.00]\end{array}$ & $9.50[6.00,15.00]$ & 0.249 \\
\hline Hospital length of stay & $\begin{array}{l}20.00[13.00 \\
32.00]\end{array}$ & $\begin{array}{l}24.00[15.00 \\
38.00]\end{array}$ & $\begin{array}{l}22.00[12.00 \\
39.00]\end{array}$ & 0.076 \\
\hline Survivors & $\begin{array}{l}25.00[16.00 \\
38.00]\end{array}$ & $\begin{array}{l}30.00[20.00 \\
44.00]\end{array}$ & $\begin{array}{l}34.00[21.50 \\
47.50]\end{array}$ & 0.001 \\
\hline Non-survivors & $\begin{array}{l}10.50[7.00 \\
17.75]\end{array}$ & $\begin{array}{l}15.00[6.00 \\
18.00]\end{array}$ & $9.50[6.00,15.00]$ & 0.192 \\
\hline
\end{tabular}

CVVHD, continuous veno-venous hemodiafiltration; CVVH, continuous veno-venous hemofiltration; RRT, renal replacement therapy.

Data are shown as median $\left[25^{\text {th }}\right.$ percentile, $75^{\text {th }}$ percentile $]$ or $\mathrm{N}(\%)$.

$P$ values in bold text indicate statistical significance at $P<0.05$.

\section{Figures}




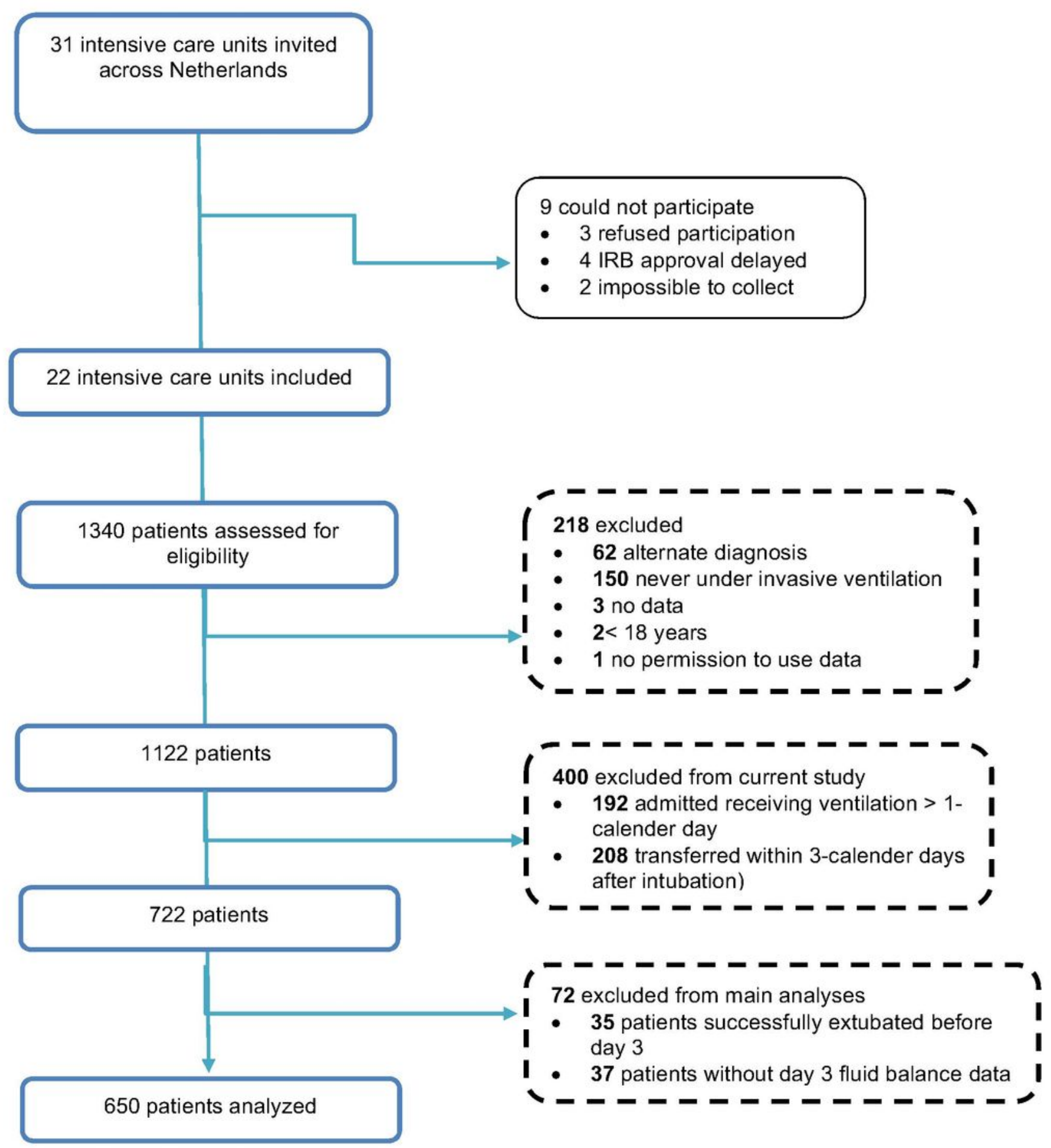

\section{Figure 1}

Flow chart of the study. 

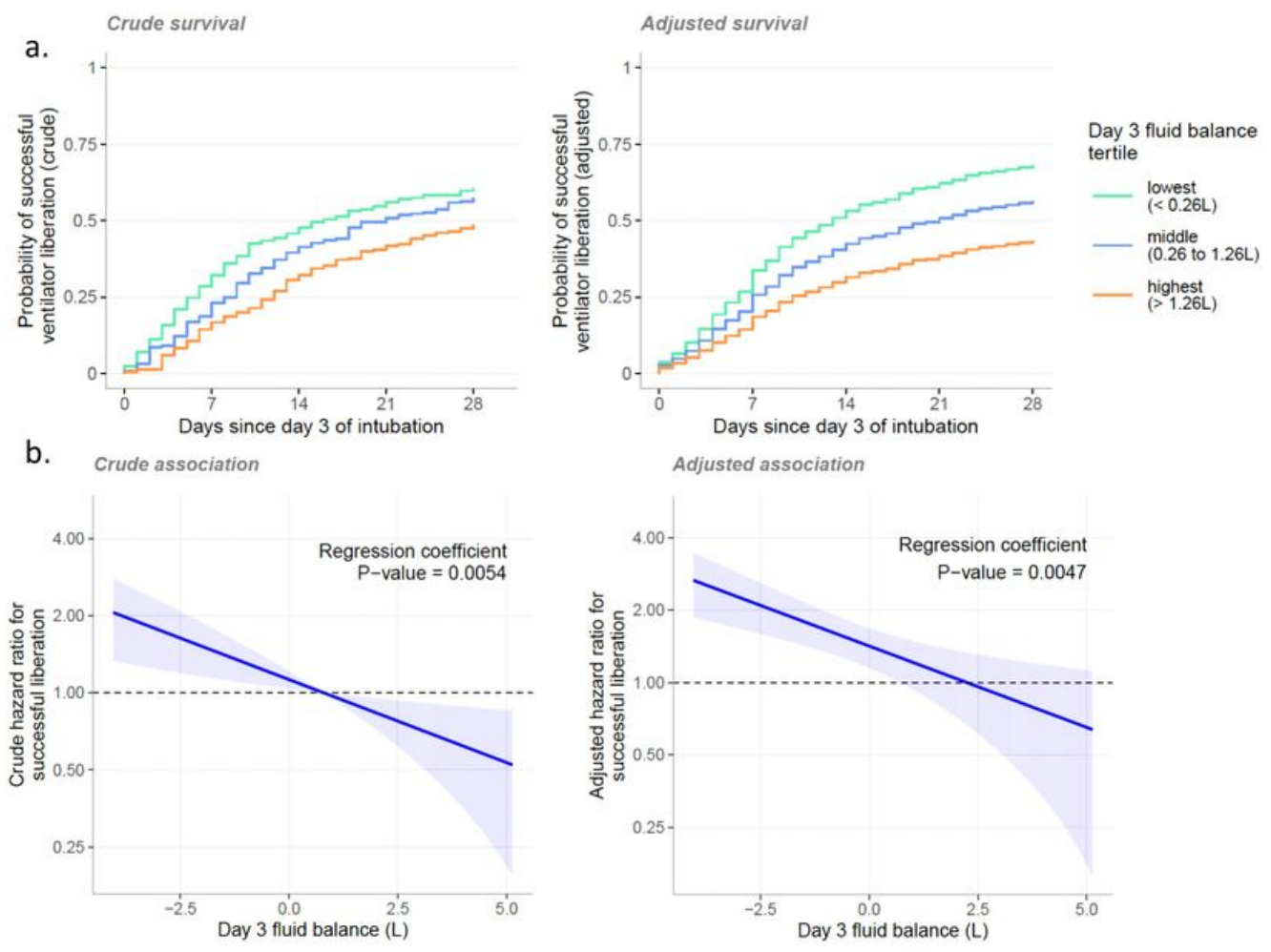

\section{Figure 2}

Survival and Marginal effect plots (a) Survival plots (unadjusted and adjusted) showing predicted probability of successful liberation of invasive ventilation as a function of day 3 fluid balance separated in tertiles. (b) Marginal effect (unadjusted and adjusted) of day 3 cumulative fluid balance on the hazard of successful liberation from invasive ventilation after adjustment for predefined confounding variables. A higher day 3 cumulative fluid balance was associated with a lower hazard (i.e., a lower probability over time) of successful liberation.

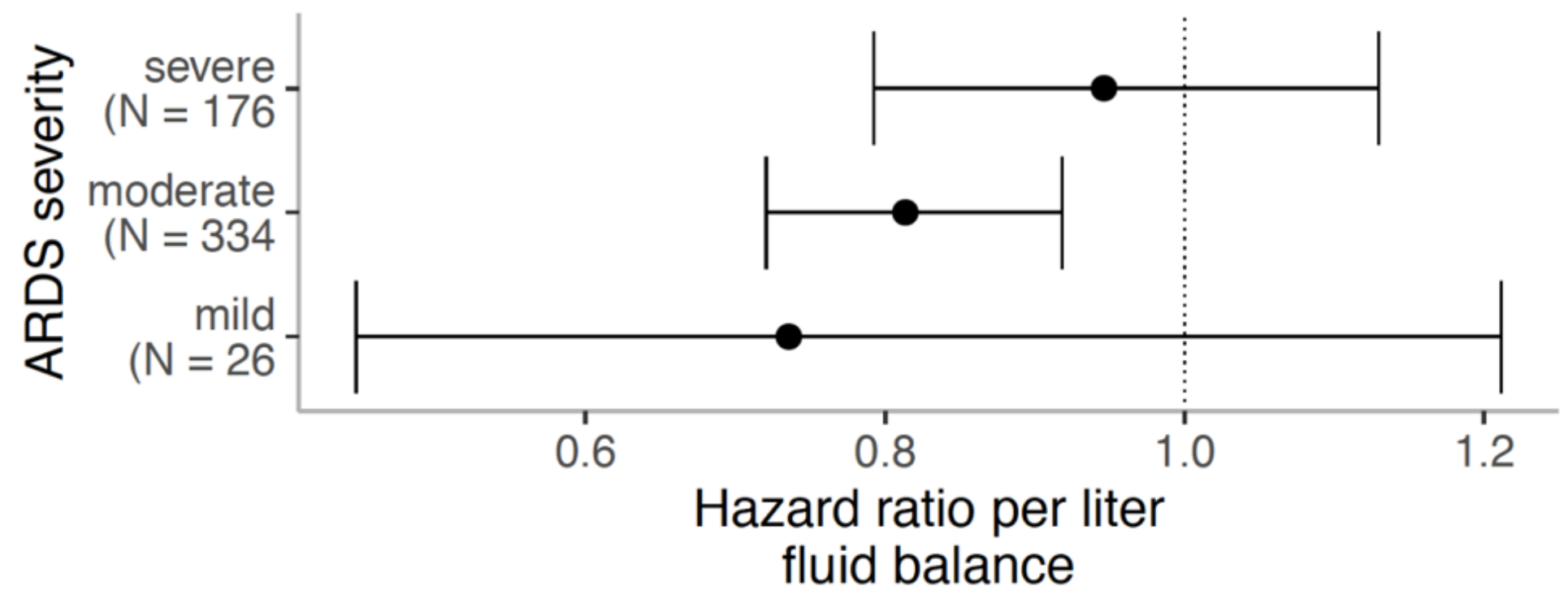




\section{Figure 3}

Sensitivity analysis showing the consistency of main effect over ARDS severity. Abbreviations: ARDS, acute respiratory distress syndrome.

\section{Supplementary Files}

This is a list of supplementary files associated with this preprint. Click to download.

- GraphicalAbstractfinal23012022.png

- SupplementAdditionalFile1CCCFB2022.docx 